\title{
The Effects of Inlet Box Aerodynamics on the Mechanical Performance of a Variable Pitch in Motion Fan
}

\begin{abstract}
A. G. Sheard
Fläkt Woods Limited, Axial Way, Colchester, Essex CO4 5ZD, UK

Correspondence should be addressed to A. G. Sheard, geoff.sheard@flaktwoods.com

Received 10 August 2012; Accepted 3 December 2012

Academic Editor: Mohammad Tawfik

Copyright () 2012 A. G. Sheard. This is an open access article distributed under the Creative Commons Attribution License, which permits unrestricted use, distribution, and reproduction in any medium, provided the original work is properly cited.

This paper describes research involving an in-service failure of a "variable pitch in motion" fan's blade bearing. Variable pitch in motion fans rotate at a constant speed, with the changing blade angle varying the load. A pitch-change mechanism facilitates the change in blade angle. A blade bearing supports each blade enabling it to rotate. The author observed that as the fan aerodynamic stage loading progressively increased, so did the rate of blade-bearing wear. The reported research addressed two separate, but linked, needs. First, the ongoing need to increase fan pressure development capability required an increase in fan loading. This increase was within the context of an erosive operating regime which systematically reduced fan pressure development capability. The second need was to identify the root cause of blade-bearing failures. The author addressed the linked needs using a computational analysis, improving the rotor inflow aerodynamic characteristics through an analysis of the inlet box and design of inlet guide vanes to control flow nonuniformities at the fan inlet. The results of the improvement facilitated both an increase in fan-pressure-developing capability and identification of the root cause of the blade-bearing failures.
\end{abstract}

\section{Introduction}

In induced draft applications, the fan extracts combustion products from a boiler. Current legislation requires boilers to be fitted with emission control systems. These systems reduce the sulphur-dioxide, nitrox-oxide and, in some cases, mercury emissions from the power plant. They also have an associated pressure loss, which the induced draft fan must overcome.

Increasingly stringent legislation has resulted in emission control systems becoming progressively more complex over the last decade. This results in a market requirement to upgrade in-service fans to cope with the associated increased system resistance. Although not reported in the open literature, the author was aware that the blade bearings situated under each blade of the variable pitch in motion induced draft fans were wearing more rapidly with each increase in fan pressure developing capability. Following the most recent upgrade, it had been necessary to replace worn out blade bearings before the scheduled five year major overhaul. The author speculated that a further increase in fan pressure developing capability was likely to exacerbate an already unacceptable situation.
The cost to upgrade an existing power plants emission control system to meet current and foreseen future regulatory requirements can be as high as $\$ 500$ million. Existing coal fired power plants have a finite life, and in order for the upgrade to make commercial sense, the value of generated electricity must be greater than the cost of upgrading and operating the power plant. The largest single cost when operating a coal fired power plant is the cost of coal. Perhaps counterintuitively, upgrading a power plants emission control system facilitates a move to lower quality coal. Without an emission control system or with a low specification emission control system, a power plant must burn higher quality low-sulphur coal to remain within existing emission limits. Once a power plant fits or upgrades an emission control system, it can burn lower quality, highsulphur coal as the emission control system will clean the exhaust gas.

The business case for fitting or upgrading an emission control systems is linked to a move from higher cost high quality coal to lower cost low quality coal. Low quality coal includes not only more sulphur, but also more silica. Silica is hard, resulting in increased wear in the ball-mills that 
grind the coal before it enters the boiler. Wear in the boiler ball-mills results in larger carbon particles that are more likely to pass through the boiler and into the induced draft fan. Consequently, the shift to low quality coal results in a shift towards an increase in the silica and unburnt carbon passing though induced draft fans. As such, an unwanted consequence of switching from high to low quality coal is to increase the rate at which fan blades erode, decreasing the fan's pressure developing capability.

The addition or upgrading of emission control equipment increases the system resistance against which an induced draft fan must operate. An increase in the fan blades' erosion rate results in the need for a further increase in fan pressure developing capability to ensure that as blades erode over the fans service life stall margin does not reduce to a point at which the fan stalls in-service. A way to increase an axial flow fan's pressure developing capability is to increase fan loading by fitting inlet guide vanes. Increased fan loading is, in practice, at the expense of fan stall margin and is therefore an inherently risky approach to increasing fan pressure developing capability in an erosive application.

Concern for maintaining a safe operating stall margin is more pressing when one places the fan downstream of an intricate duct system, as is typically the case with induced draft fans. The inlet flow distortion associated with an intricate duct system results in an "installation effect" that reduces fan stall margin. When examining the consequence of installation effect, the bulk of published works has focused on noise generation $[1,2]$. Installation effects invariably degrade cooling fans' acoustic performance; however, acoustic considerations are not of primary concern for fans in induced draft application. We can lag induced draft fans to reduce acoustic emissions. The primary consideration for an induced draft fan is the aerodynamic impact of a nonasymmetric inflow, with a particular concern for reduced fan efficiency and stall margin. Some researchers, notably Roslyng [3] and Staiger and Stetter [4], have studied the aerodynamic impact of fan installation effects. Despite the undoubted quality of the reported research, neither was able to generalize their results in a way that facilitated application beyond their work.

The impact of erosion on induced draft fan performance has also received relatively little attention in the literature. However, Corsini et al. [5] have studied the impact of erosion on induced-draft fan leading edge geometry. They concluded that three factors dominate the erosion process: (i) the inflow's incidence angle, (ii) the flow deviation correlated to the blade profile, and (iii) the blade tip speed. Corsini et al. [6] continue their work, developing a computational method to predict erosion rate and the time it takes to erode the induced-draft fan blades to the point where they were no longer able to generate the necessary pressure rise to avoid the fan stalling at its design point. Corsini et al. [7] reported the eroded blade profile at different blade angles, and were able to computationally establish the characteristics of both the datum fan, with blades as per the design intent and eroded blades. The erosion occurred over approximately 12,000 hours in-service operation, corresponding to less than two years continuous operation. Corsini's research team removed the eroded blades when the fan efficiency fell so far that the motor driving the fan was no longer able to supply sufficient power to maintain the required fan duty point.

In the present study, the author models the inlet duct, inlet guide vanes, fan rotor, and stator. He initiated this in response to an in-service issue. A facility operator had incorrectly specified a $1767 \mathrm{~mm}$ diameter single stage induced draft fan with too low a pressure developing capability. The blade bearings also suffered premature failure. The fan's installed inlet configuration was complex, leading to the inlet flow's significant distortion which reduced fan performance. In combination with the fan's underspecification, the performance reduction that occurred as a consequence of the poorly conditioned inlet flow resulted in the fan limiting the power station power output. The author initiated the computational program of work in an effort to both increase the fan pressure developing capability and identify the root cause of the premature blade bearing failure.

We can configure induced draft fans with a rectangular inlet box that accepts flow coming vertically down. The box turns the flow ninety degrees and into a round and horizontal fan inlet. The study used computational analysis as a "numerical laboratory". This provided insight into the fan's actual inlet flow field. The objective was to facilitate inlet guide vane design improvement. The desired outcomes were first, an increase in fan pressure development capability and, second, an understanding of the aerodynamic mechanism that was driving the fan blade bearings' premature failure.

\section{Computational Analysis}

The author analysed the geometry of a $1767 \mathrm{~mm}$ single stage induced-draft coal fired boiler fan as installed in a power plant, but with a standardized air inlet system. Greenzweig et al. [8] experimentally studied the effect of actual inservice air inlet system installations on induced draft coal fired boiler fan performance and concluded that the effect of inlet flow distortion on fan performance was significant, with the effect varying with the rating point's position along the fan curve. They found distortion effects greater at higher flow conditions and lower at lower flow conditions. This observation led Greenzweig et al. [8] to conclude that the actual impact of inlet distortion is dependent on the relationship between the fan design parameters, and further that engineers currently do not understand the relationship between these parameters.

The relationship between fan design parameters and the impact of inlet flow distortion on fan performance is a subject in its own right. In the current program of work the author's focus was not an experimental research program aimed at the elucidation of physical mechanisms underpinning the effect of flow distortion on fan performance. The author's focus was developmental, aimed at applying computational methods to improve the performance of an existing in-service fan. In addition, the author was able to use the computational results to provide insight into the circumferential variations in the flow field that then assisted him in identifying the root cause of the observed 
TABle 1: In-service duty point and specification of the PFS fan studied in the reported research.

\begin{tabular}{|c|c|c|}
\hline \multicolumn{3}{|l|}{ Fan in-service duty point } \\
\hline Pressure $(\mathrm{Pa})$ & & 2245 \\
\hline Flow $\left(\mathrm{m}^{3} / \mathrm{s}\right)$ & & 54.3 \\
\hline Blade angle (degrees) & & 56.0 \\
\hline \multicolumn{3}{|l|}{ Fan rotor data } \\
\hline Blade number & & 18 \\
\hline Hub-to-casing diameter ratio & & 0.7 \\
\hline Tip diameter (mm) & & 1767 \\
\hline Rotor tip clearance (\% span) & & 6 \\
\hline Rated rotational frequency (rpm) & & 890 \\
\hline Fan blade geometry & Hub & Tip \\
\hline Chord (mm) & 487 & 446 \\
\hline Solidity & 1.48 & 0.96 \\
\hline Stagger angle (degrees) & 38 & 60 \\
\hline Camber angle (degrees) & 45 & 36 \\
\hline
\end{tabular}

in-service premature blade bearing failure. As such, the author chose to study the in-service fan with a standardized inlet. This standardized inlet was both used in model testing to establish the fan's characteristics and modeled in the author's computational code when predicting the fan's characteristics.

The fan that is the subject of this research is designated Pan Fläkt Single (PFS), where "pan fläkt" in Swedish means "boiler fan" and "single" designates a single stage fan, Table 1. The author derived the studied fans characteristics, Figure 1, from data that he obtained using a low speed $1250 \mathrm{~mm}$ aerodynamic fan model. The aerodynamic model had the correct tip solidity and hub ratio, with model test data scaled to the studied fan speed and diameter using the fan laws. The author selected the studied fan for induced draft application in a power plant, with a duty point that is typical for the application, Figure 1 and Table 1. The duty point falls below the fan's operating characteristic peak efficiency region as induced draft applications are classically an erosive application. Fan blade erosion reduces the fan's pressure developing capability, and therefore one must select the fan conservatively to accommodate a reduction in stall margin over the fan's service life.

The author modeled the studied fan with a standardized inlet box, rotor, stator, and diffuser, plus a section of an expansion chamber, Figure 2. The inlet box comprised a square section vertical intake angled through ninety degrees and converted into a circular inlet. A shaft fairing traversed the inlet duct's lower part and expanded in a conical form onto the fan annulus. Following Teixeira et al.'s method [9], the author placed a fan with outlet guide vanes downstream of the inlet box discharging into a conical diffuser.

In the original configuration, the author fitted five long chord sheet metal stays connecting the fan's hub surface to the outer casing, Figure 3. This original configuration was symmetrical with respect to a vertical plane through the fan center line, with the stays' primary purpose as the provision

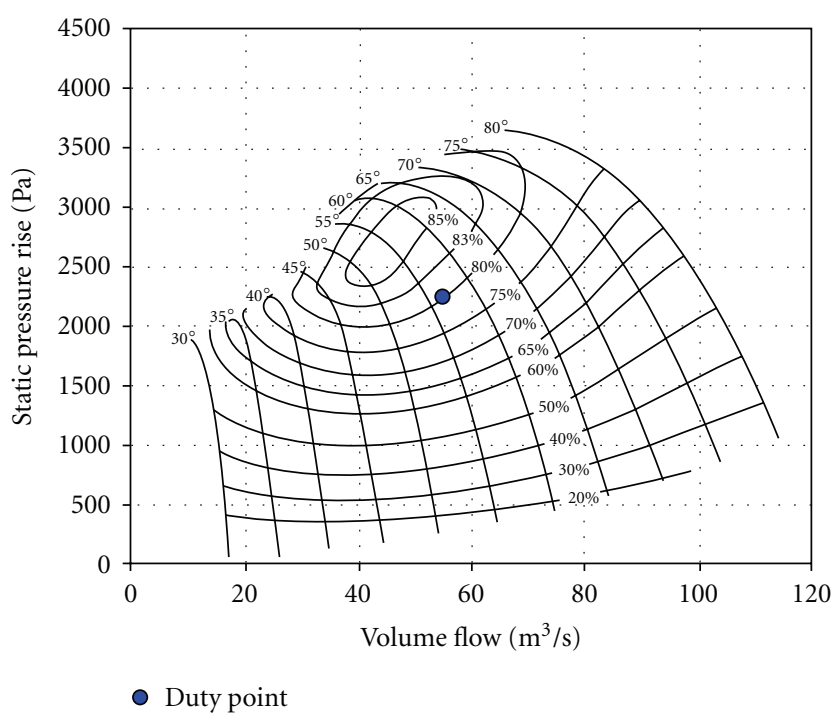

FIGURE 1: The performance characteristics of the studied $1767 \mathrm{~mm}$ diameter PFS fan. This fan chart has been scaled from experimental data which the author obtained using a $1250 \mathrm{~mm}$ low speed aerodynamic model, scaled for speed and diameter using the fan laws.

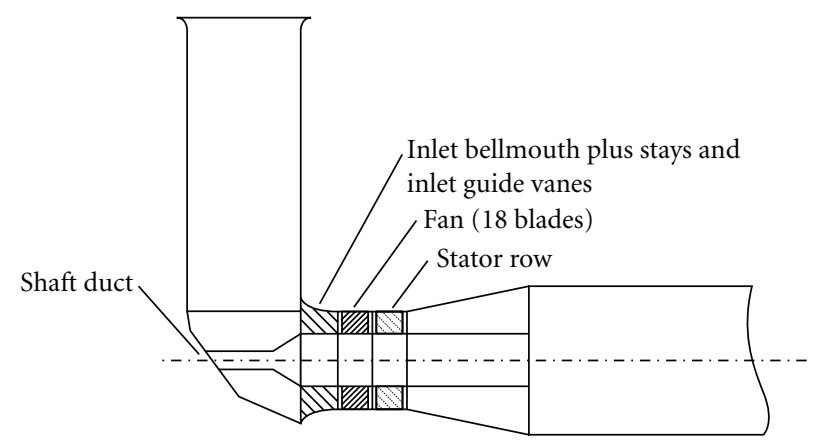

FIGURE 2: Side elevation of the fan installation arrangement.

of structural strength. The stays themselves were intended to present as near a neutral aerodynamic effect as possible.

The author studied multiple variations of stay and inlet guide vane arrangements. He obtained the greatest increase in fan pressure developing capability and reduction in circumferential variation in pressure when a further three stays and eight short chord inlet guide vanes supplemented the original five stays, Figure 3. This improved eight stay plus eight inlet guide vane configuration was circumferentially symmetrical, with the additional stays and guide vanes requiring no original stay modification. In this way the author could retrofit the improved configuration to the original configuration without compromising the fan's structural integrity. The computational results, Figure 3, are for the original five stay and improved eight stay plus eight inlet guide vane configurations.

2.1. Aerodynamic Details. The inlet box introduced the initial aerodynamic complexity, where vertical inlet flow turned through 90 degrees from a square-section duct into an 


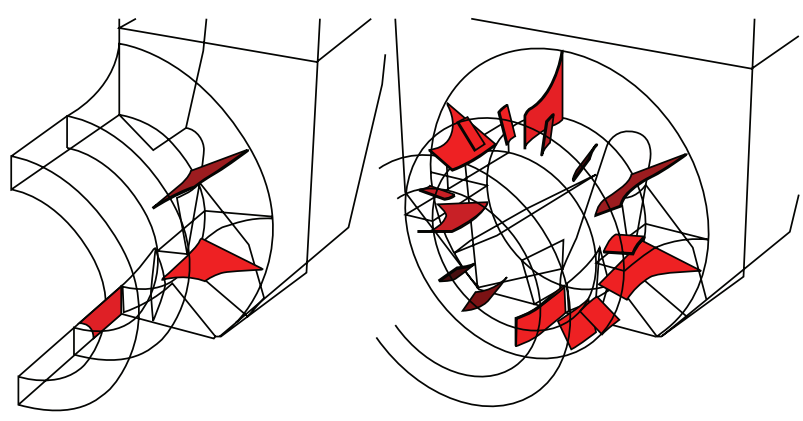

FIGURE 3: The original five stay configuration, left, and improved configuration with eight stays plus eight guide vanes, right.

annular intake, while accommodating a sizeable shaft fairing. The annular intake incorporates the original five stays. The improved configuration supplements the original five stays with an additional three cambered stays, plus cambered chord-wise extensions to the original five stays. The eight additional inlet guide vanes associated with the improved configuration were also cambered. The resultant effect was that the improved configuration preswirled the inlet flow into the fan and increased fan aerodynamic loading. Additionally, by varying the camber on each stay and inlet guide vane, the author aimed to minimize circumferential variations in the fan rotor inlet flow which the inlet box configuration introduced.

For the fan, an effect of additional loading is a shift of the characteristic upwards and to the right. Hence, for a given flow rate, the fan produces a higher pressure by operating further along its characteristic. This last point implies an unavoidable reduction in stall margin. The additional loading will also result in some decrease in fan efficiency. However, for a well-designed blade that was, in practice, operating at a duty point below peak efficiency, the increased loading may bring the actual fan operating point closer to the peak efficiency operating point. Operating closer to the fans peak efficiency will go some way towards offsetting the efficiency decrease associated with increased fan loading.

2.2. Objective of the Simulations. The study's primary objective was to safely maximize the fan loading through the addition of stays and inlet guide vanes. The author sought evidence of separation throughout the blade span, as well as information about rotor inlet flow conditions' possible pitchwise variations. Additionally, the author used the simulations to gain a deeper understanding of the flow field in the inlet box and ultimately to provide information to enable elimination or, at least, minimization of sources of inefficiencies which he identified in the computational results. The author obtained solutions for four flow conditions: duty point, $10 \%$ and $20 \%$ above and $5 \%$ below the duty point condition.

The author computed two forms of the inlet box, the original five stay configuration and the improved eight stay, plus eight inlet guide vane configurations. The original configuration was symmetrical around a vertical plane through the fan center line, and therefore the author was able to model only half the inlet box. This simplifying assumption is not applicable to the improved configuration. The author varied the camber that was associated with each stay and inlet guide vane in an attempt to minimize the circumferential variation in outlet flow from the stays and inlet guide vanes. Consequently, each stay and inlet guide vane had a different camber, and therefore required the author to model the full annulus.

\section{Computational Tool}

The computational fluid dynamics code that the author employed in the present study was CFX-TASCflow, Version 2.11.1. The author used a strongly conservative finite element-based finite volume discretisation method to partition the physical domain into a set of hexahedral control volumes. Shape function usage introduces the finite element connection which the code employs to define subelemental geometry coordinates which are connected with the assembly of the control volumes. The author carried out all computations with the standard $k-\varepsilon$ turbulence model with standard wall functions.

Out of the possible discretisation schemes available, the current simulations employed the Modified Linear Profile Scheme (MLPS). The MLPS gives second order error reduction in most instances [10]. For steady-state computations, the code employs a transient formulation as a convenient means of introducing relaxation into the iterative nonlinear solution [11]. If only the steady-state solution is of interest, one can use the time step $\Delta t$ as a free parameter through which it optimizes the convergence rate. This corresponds to the use of pseudotime which one employs solely to advance the solution in an iterative manner.

The relaxation scheme which one employs in the code belongs to the Lower-Upper (LU) factorization family. The code makes use of a multigrid solution acceleration technique designed to reduce the global linear residuals in between the solution of the nonlinear terms. The rationale underpinning multigrid acceleration is rooted in the observation that iterative solvers tend to reduce errors which correlate with short grid spacing much faster than they do to those which correlate with longer lengths.

When running the inlet box simulations, it was appropriate to displace the outlet boundary conditions location away from the bell-mouth discharge and for this purpose the author added an annular ducting grid section to the model. The grid that the author employed in the second set of simulations includes rotor and stator blocks, a conical diffuser and a long expansion chamber, Figure 4. Although the mesh's extent is large in this last component, it is useful to have the outflow boundary located far downstream of a backward step, thereby preventing recirculation flow occurrence in the boundary's proximity since this can act as a source of overall convergence problems. The grid sizes are about 600,500 nodes for the original configuration of five stays and 1,200,000 nodes for the improved eight stay plus eight inlet guide vane configuration. The number of nodes that the author needed for the improved configuration was approximately double that of the original as a consequence of the requirement to extend the original configuration's 


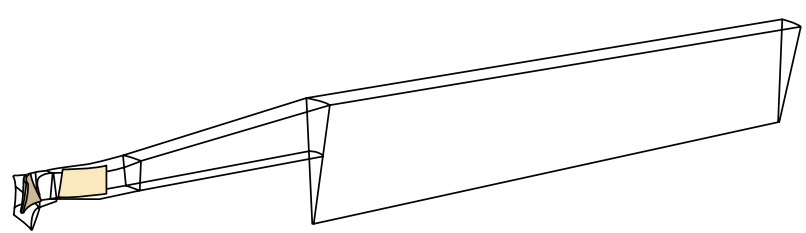

Figure 4: Rotor, stator, diffuser, and expansion chamber computational domains.

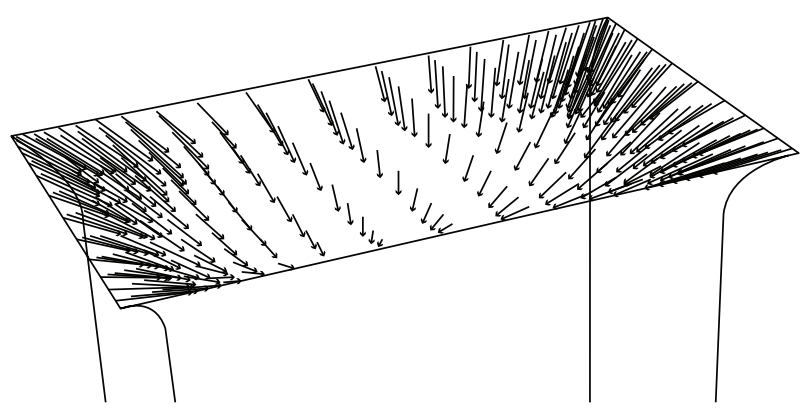

FIgURE 5: Prescribed flow direction vectors at the fan duct inlet.

half-annulus model to a full-annulus model. The author augmented both simulations with an inlet box grid that comprised 325,000 nodes.

\section{Simulation Parameters}

The author specified the boundary conditions applicable to the two simulations as total pressure and flow direction at inlet and mass flow at outlet. The author ran both the original and improved inlet box configuration simulations with prescribed inlet profiles. The prescribed inlet profiles' function was strictly that of aligning the flow with the local geometric features given that earlier runs had shown that a prescribed uniform direction, taking no account of these features, induces the appearance of lengthy low momentum flow structures along the inlet duct walls and corners. With a prescribed inlet profile the flow direction's local distribution in the form of a vector plot is indicative of a well-conditioned inlet, Figure 5.

The author performed the computations in this study on six $1.5 \mathrm{GHz}$ twin-processor PCs networked as a Linux cluster. In this platform, and employing two CPUs in parallel, each computation of the original five stays configuration took approximately $45 \mathrm{CPU}$ hours to perform and 1700 iterations to reach a maximum root mean square residual error of $3 \mathrm{E}-$ 06.

\section{Inlet Box Simulation Results}

An analysis of simulation results of the original five stay configuration illustrated that the flow was generally well behaved without any significant areas of separation and that downstream of the stay outflow plane the flow is predominantly axial, notwithstanding the presence in places of a small amount of tangential secondary flow. This translates into a two to four degree departure from a zero rotor inflow angle
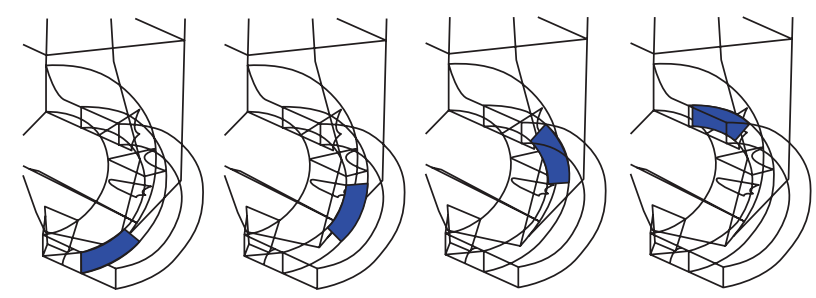

FIGURE 6: Flow averaging angular sectors for the original five stay configuration.

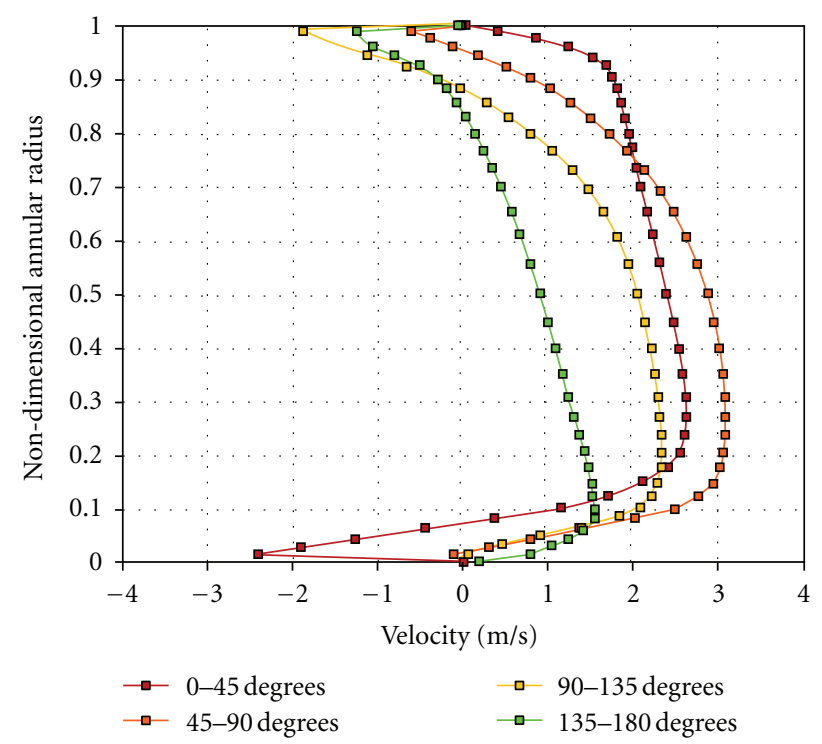

Figure 7: Tangential velocity radial distribution at the inlet box discharge for the original five stay configuration at the duty point condition.

at given pitch-wise locations. For the purposes of supplying the corresponding fan assembly model with an inlet profile, the author divided the inlet box outflow into four 45-degree sectors, Figure 6. Figure 7 presents a comparative plot of the sector-averaged tangential velocity. The flow's positive direction is in a clockwise sense when looking upstream of the discharge plane.

The author applied a similar postprocessing method to the improved eight stays plus eight inlet guide vane configuration and therefore the equivalent tangential velocity plot shows results for eight pitch wise sectors of 45 degrees, Figure 8 . The origin of angular displacement measurement is as for the five stays case.

The effect of fitting the cambered stays and inlet guide vanes to the improved configuration is apparent, but the comparisons with the original configuration are limited to equivalent sectors alone. Unlike the complete inlet box arrangement, the tangential flow distribution in the five stays geometry is valid only for the side of the box which the author computed. Under the flow symmetry assumption, the opposite side will present a similar distribution, but flowing in the opposite direction. One must then superimpose the inlet box's "handed" effect in its original configuration onto the overall spinning motion which the added turning effects 


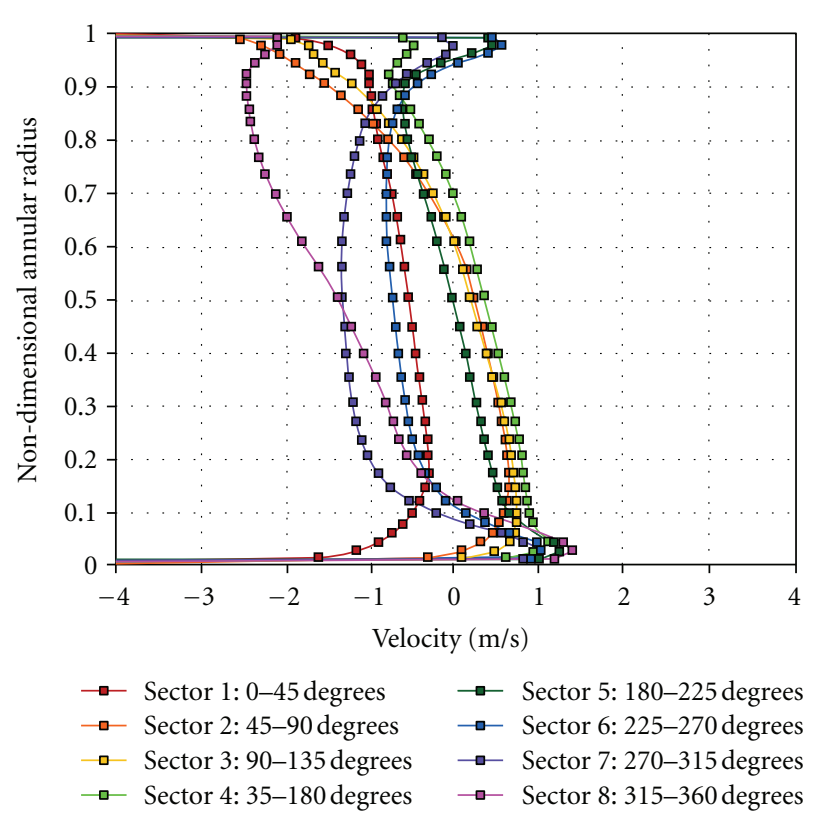

Figure 8: Tangential velocity radial distribution at the inlet box discharge for the improved eight stay plus eight inlet guide vane configuration at the duty point condition.

induce, but it is not immediately obvious what this should be locally.

A closer analysis of the results, Figure 8, can help clarify the issue associated with the handed effect since, in general, the velocity distribution in related sectors for the two plots is broadly similar and corresponds mostly to the highest values. Conversely, the lowest values are those which would match the geometric opposite's sectors of the computed five stays domain confirming, therefore, the notion that the flow's right hand side in the inlet box contributes towards the swirling motion, while that of the left hand side tends to oppose it.

\section{Fan Simulation Results}

The second simulation set addressed the combined geometries of the rotor, stator, diffuser, and downstream channel with the inflow boundary conditions supplied to the simulations which the author obtained from the inlet box computations at the appropriate flow rates. The original five stays configuration computation involved the study of four flow conditions corresponding to the pitch-wise sectors described above, while the author carried out that of the eight stay plus eight inlet guide vanes for the corresponding points at the eight circumferential positions.

The author presented the fan simulation results for the original five stay configuration on the fan characteristic derived from model test data, Figure 9. The duty point pressure is slightly over predicted, and the slope of the simulation results is lower than the model test data. The over prediction of the duty point pressure is small enough for us to consider within the combined uncertainty of the model test data and simulation results. The lower slope of the simulation results implies that the simulation is under

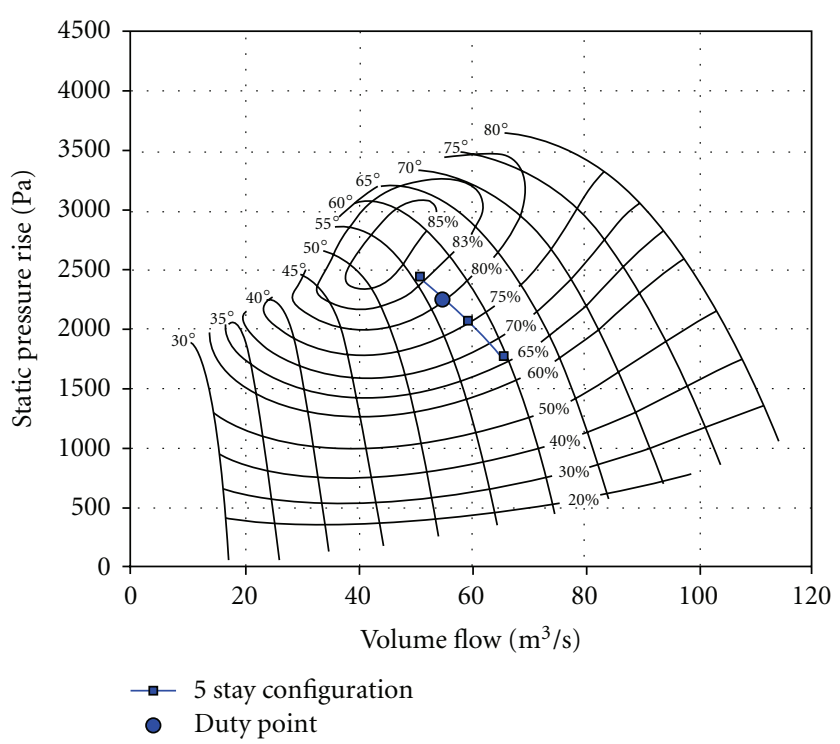

Figure 9: Experimentally derived characteristics for the studied $1767 \mathrm{~mm}$ diameter PFS fan, with simulation results for the original five stay configuration at four flow conditions, duty point, $10 \%$ and $20 \%$ above and $5 \%$ below the duty point condition.

predicting the fan's peak pressure developing capability and is therefore conservative and consequently acceptable.

The author neither model tested nor performance tested in-service the improved eight stay plus eight guide vane configuration. Consequently, the author presented the improved configuration fan simulation results in a comparative manner between the simulation results for the original and improved configurations. The author compared the rotor relative inflow angles for the two configurations for equivalent angular sectors at the duty point, Figure 10. The author predicted that the mid-height rotor relative inflow angle would increase by approximately five degrees with the change from original to improved configuration. The author estimates that in-service, the fan's motor had a margin on peak power sufficient to allow inflow angle to increase by up to seven degrees, with five representing a conservative maximum.

The effect of increasing inflow angle on fan pressure rise is to increase predicted duty point pressure from $2320 \mathrm{~Pa}$ to $3300 \mathrm{~Pa}$, Figure 11. It is apparent that besides the expected increase in pressure with the change from original to improved configuration, there is a marked change in the characteristic lines gradient which is consistent with a movement towards stall. Despite moving towards stall, the simulation results do not predict that the improved configuration will stall at the duty point. As the original configuration did predict the fan's stall margin conservatively, the improved configuration's stall margin was acceptable.

An analysis of the simulations adiabatic efficiency results for both the original and improved configurations indicates that the improved configuration has a duty point efficiency approximately $1 \%$ less than the original configuration, Figure 12. This is consistent with the principle that for a well-designed blade increasing the rotor relative inflow angle 


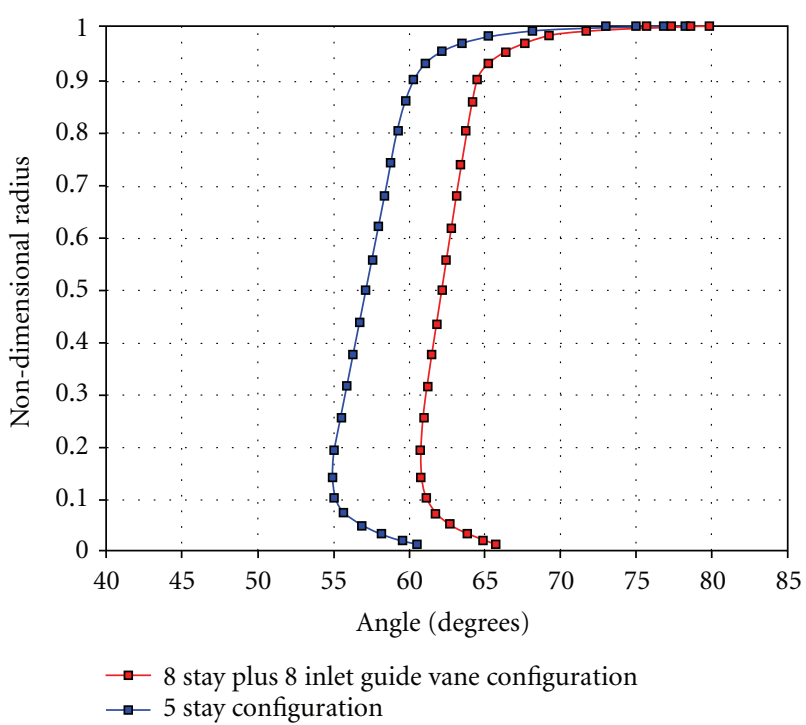

Figure 10: Radial distribution of the blade relative inflow angle for the original five stay and improved eight stay plus eight inlet guide vane configurations at the duty point condition.

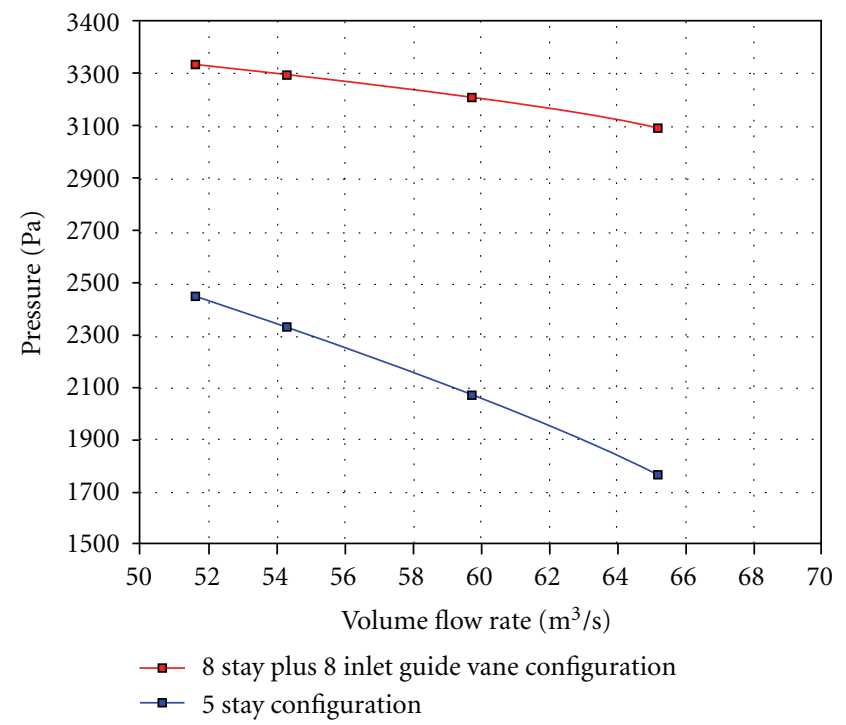

FIGURE 11: Total pressure rise for the original five stay and improved eight stay plus eight inlet guide vane configurations for four flow conditions: duty point, $10 \%$ and $20 \%$ above and $5 \%$ below.

should equate to some local increase in losses. Although the simulation results for the duty point confirm increase in losses, the simulation results indicate that at higher flow, the improved configuration is able to maintain efficiency more effectively than the original configuration. The improved configuration's ability to maintain efficiency at higher flow suggests that when considering the rotor in isolation, there is a small reward for operation with a higher relative inflow angle.

The improved eight stay plus eight inlet guide vane configuration increases the fan aerodynamic loading. Increasing fan aerodynamic loading also increased fan acoustic emissions [12]. When we analyze the improved eight stay

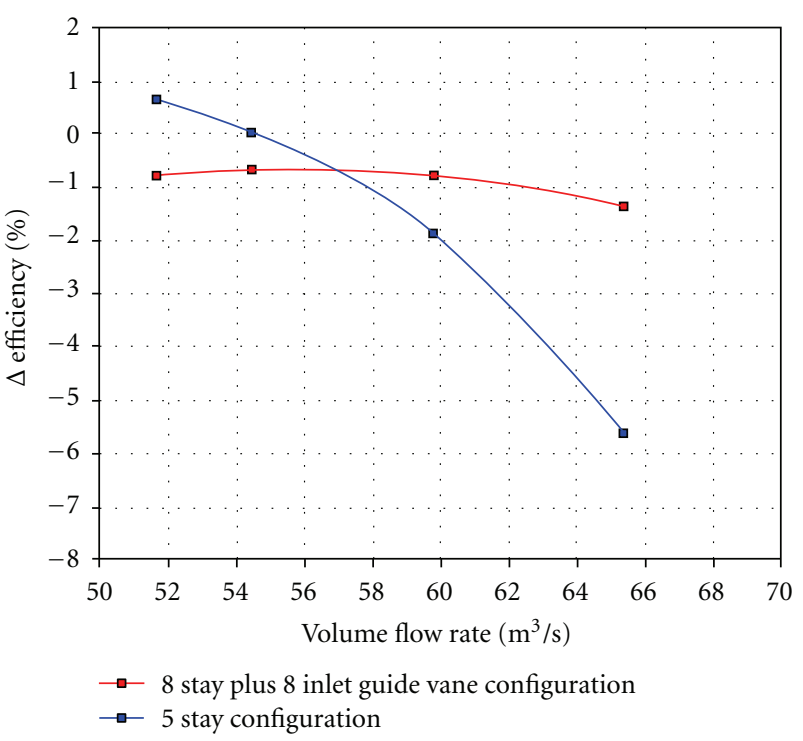

FIGURE 12: Normalized efficiency variation relative to the duty point for the original five stay and improved eight stay plus eight inlet guide vane configurations for four flow conditions: duty point, $10 \%$ and $20 \%$ above and $5 \%$ below.

plus eight inlet guide vane configuration using Pascu et al.s method [12], we can predict an overall increase in fan acoustic emissions of between 3 and $5 \mathrm{~dB}$. In practice, the author installed the original configurations and then later retrofitted the improved configuration into the same fan. The fan was located next to the boiler of a coal fired power plant, and in close proximity to other heavy duty rotating equipment. This proved impossible in practice to accurately measure on-site fan acoustic emissions with either the original or improved configuration. As such, the author was not able to ascertain that the change in stay and guide vane geometry resulted in an increase in fan acoustic emissions; however, it is likely that if the background noise in the fan's vicinity had been lower, an increase would have been apparent.

\section{Mechanical Impact of Fan Simulation Results}

The author undertook the computational analysis in response to an in-service issue with an induced draft fan. The induced draft fan was not generating the required pressure. The inability to produce the required pressure was a consequence of the fan's under-specification for the application in the first place. It was subject to a distorted inlet flow and also suffered significant erosion as a consequence of a poorly installed and maintained air filtration system upstream of the fan. The improved stay and inlet guide vane configuration increased the fan pressure developing capability, and additionally reduced the circumferential variation in velocity entering the fan blades. The author considered this reduction in circumferential velocity as important as a consequence of a second in-service issue with the induced draft fans generally: premature blade bearing failure. 


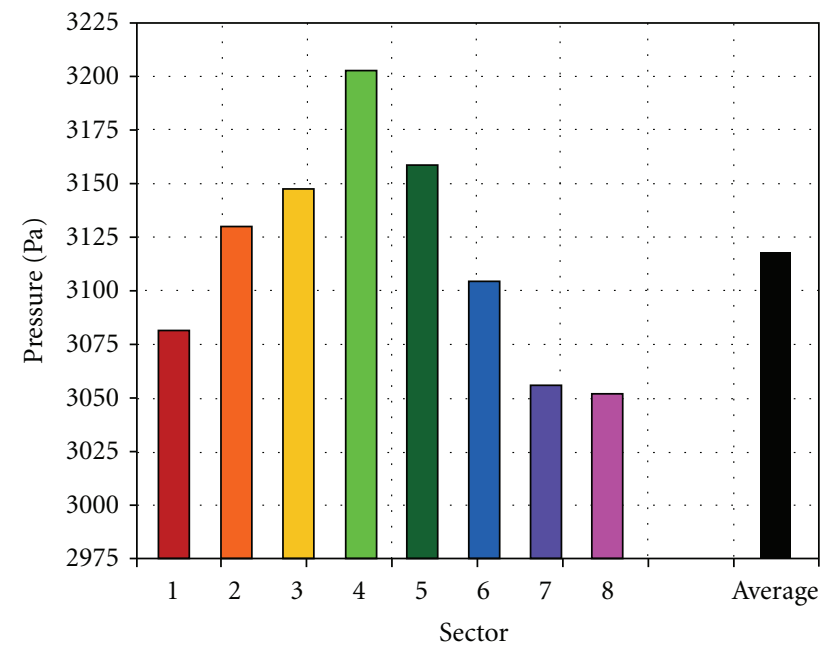

口 Sector 1: 0-45 degrees ㅁ Sector 2: 45-90 degrees $\square$ Sector 3: 90-135 degrees

$\square$ Sector 4: 35-180 degrees

Sector 5: 180-225 degrees

- Sector 6: 225-270 degrees

ㅁ Sector 7: 270-315 degrees

ㅁ Sector 8: 315-360 degrees

FIGURE 13: Total pressure variation with pitch-wise sector for the improved eight stay plus eight inlet guide vane configuration at the duty point condition.

Collected data downstream of the rotor for the improved eight stay plus eight inlet guide vane configuration, Figure 13, shows the predicted cyclic variation in total pressure due to the uneven pressure distribution emanating from the inlet box. The graph's scale exaggerates the true magnitude of the dissimilarity between different sector values. The maximum deviation from the average value is $2 \%$. This deviation, due to the inlet box conditions, is small enough for us to regard as aerodynamically negligible.

Despite that observation that the uneven pressure deviation's aerodynamic effect due to the inlet box conditions may be neglected, we must consider it within the context of the studied fan: a constant speed variable pitch in motion fan. A blade bearing that facilitates change in blade angle supports each fan blade to enable fan-load adjustment. The deviation in aerodynamic load results in a once-per-revolution cyclic load and moment on each blade which then changes the load distribution on the blade bearing, Figure 14. This onceper-revolution load results in the bearing balls' cyclic contact angles on the bearing raceway. The cyclic twisting moment causes an infinitesimal rotation in pitch change direction, which then results in bearing ball orbital motion which is different for each ball.

A consequence of the ball orbital motion is that bearing balls tend to migrate towards one location on the bearing raceway [13]. The balls push until they remove all clearance, with the resultant ball to ball separator forces becoming large. This ball to ball separator force results in increased bearing friction due to the friction between bearing balls and ball separator. This results in accelerated ball separator wear, Figure 15, and consequently, bearing ball wear. The result is the bearing's rapid mechanical deterioration, and consequently, it rapidly increases forces to change the blade angle.

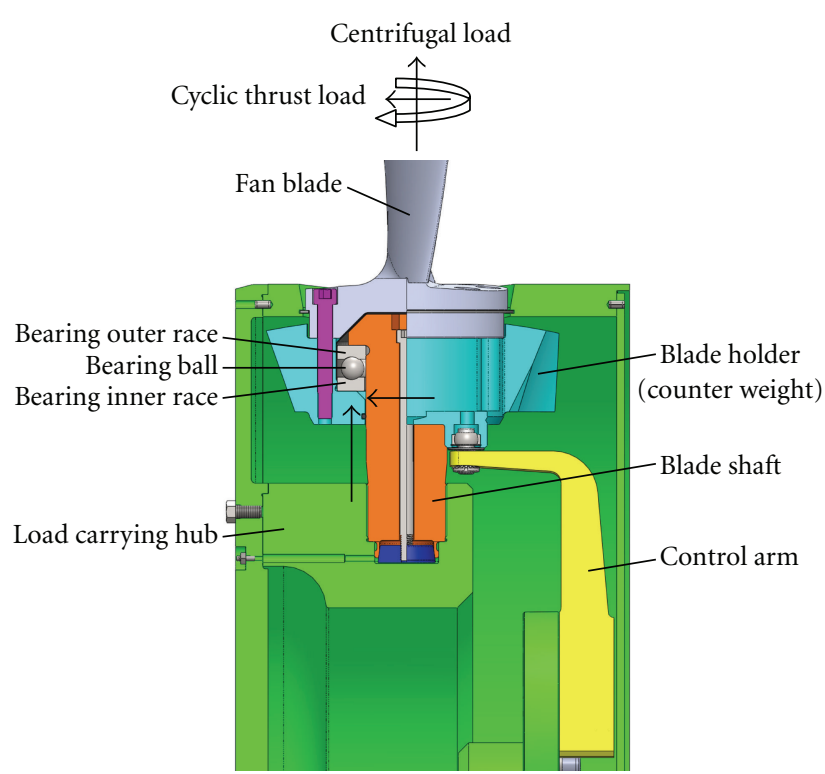

FIGURE 14: Mechanical loads induced in the blade bearing by the pitch-wise total pressure variation.

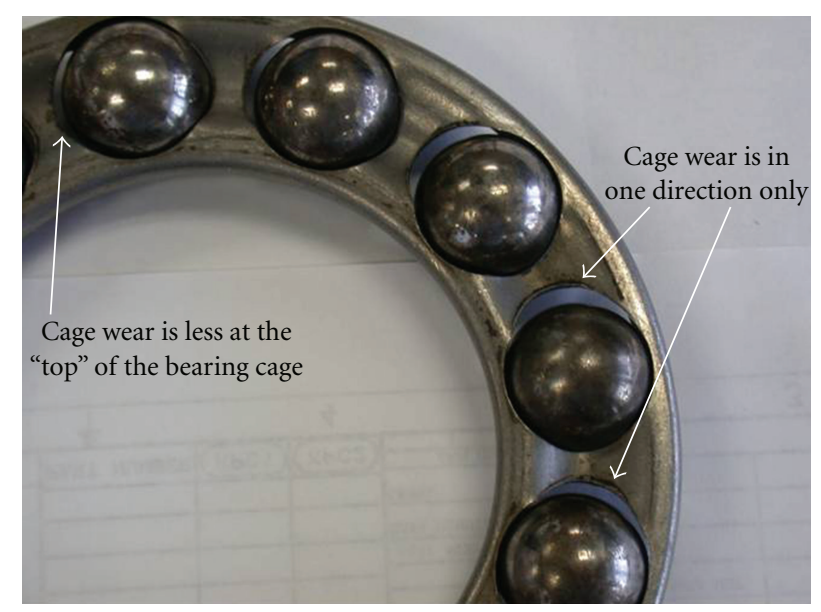

Figure 15: Wear in a traditional "cage" bearing separator that occurs as a consequence of mechanical loads on blade bearing balls. Pitch-wise total pressure variations induce the mechanical loads.

Reducing the cyclic variation in total pressure due to the uneven pressure distribution emanating from the inlet box below $2 \%$ would be difficult to achieve in practice in an industrial fan application. Rather than attempting to eliminate the uneven pressure distribution, Sheard and Rhoden [14] proposed a novel bearing separator comprising individual bearing separator elements, Figure 16, manufactured from a low friction carbon impregnated Teflon. The resulting bearing configuration, Figure 17, has the same imposed mechanical loads that previously resulted in bearing separator wear (Figure 15). However, the use of separate bearing separator elements results in the imposed loads inducing rotation in each separator that then transports lubricant into the bearing ball to bearing separator contact zone. 


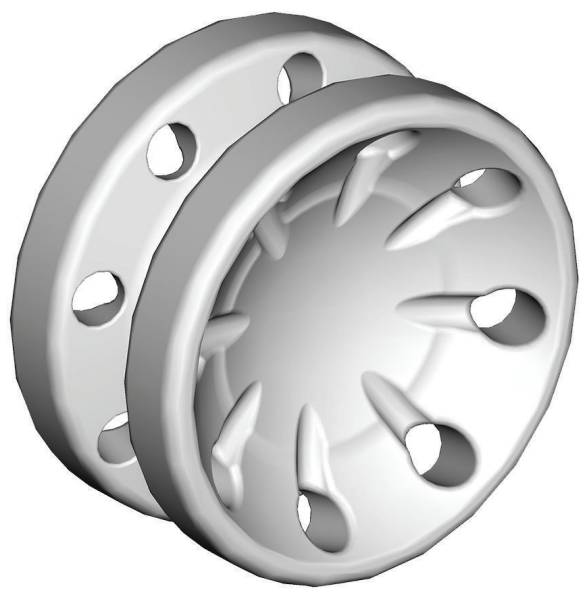

FIGURE 16: Sheard and Rhoden's bearing separator concept [14].

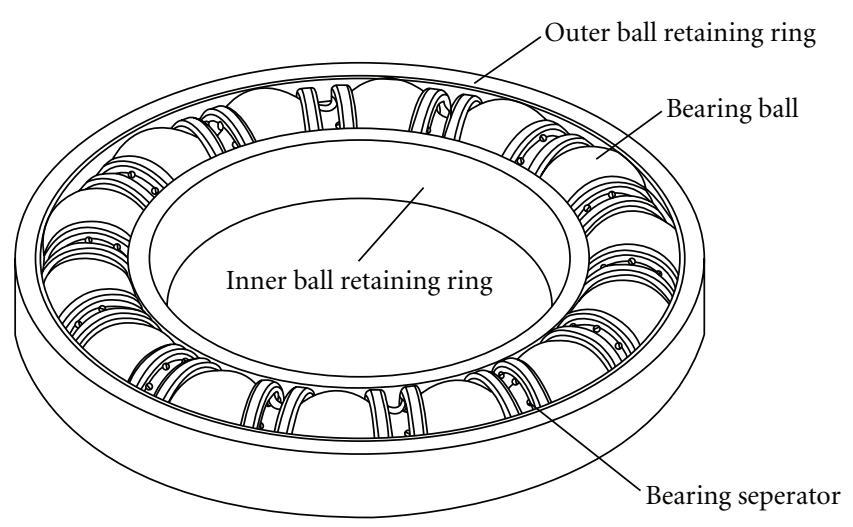

FIGURE 17: A blade bearing, fitted with Sheard and Rhoden's bearing separator [14].

Sheard and Rhoden's bearing separator design [14] has demonstrated good in-service reliability, withstanding the imposed loads that arise with the cyclic variation in total pressure due to the uneven pressure distribution emanating from the inlet. An investigation after 22,000 in-service hours indicated that approximately $50 \%$ of bearing life had been consumed. The bearing itself was still well packed with lubrication that showed good persistence in all contact areas within the bearing. The bearing balls, separator, and raceway showed no visible signs of damage.

\section{Conclusions}

The author studied an inlet box in its five stays original form and an improved configuration with eight stays plus eight inlet guide vanes, designed to pre-swirl the flow before discharge onto a fan stage. The two inlet box simulations enabled the identification of handed flow effects in the original configuration which are still present in the improved configuration in the form of small, but detectable tangential speed variations. The corollary is that for complex inlet assembly geometries, particularly for higher speed applications, there is a need to account for the cumulative flow effects in order to avoid discharged flow pitch-wise nonuniformities. We can best meet this objective through some form of computational method which is able to resolve the three dimensional flow-field. For the case under study, the fan's stall margin in its original configuration is adequate to accommodate the additional loading associated with the improved configurations additional stays and inlet guide vanes. Nevertheless, the fan remains susceptible to erosion effects.

The analysis of the improved eight stays plus eight inlet guide vanes rotor-stator simulations over the eight pitch-wise sectors enabled the identification of a $2 \%$ cyclic variation in pressure due to the uneven pressure distribution emanating from the inlet box. Although the aerodynamic impact is small, there is a mechanical consequence for the studied variable pitch in motion fan. The resultant mechanical loads on the blade-bearing result in the bearing ball separator's rapid wear and consequently, premature blade bearing failure. The author developed a novel bearing separator design that has proven capable of withstanding the imposed mechanical loads and thus eliminating the need to reduce further the cyclic variations in total pressure. After 22,000 hours in-service operation, the author estimated that the blade bearings fitted with the novel bearing separator had approximately $50 \%$ bearing life remaining. As such, the novel bearing separator design facilitates an estimated five year bearing life, self-consistent with the major service intervals of variable pitch in motion fans in induced draft application.

\section{References}

[1] A. Guédel, "Prediction of the noise installation effect induced by a bend at the inlet of an axial flow fan," in Proceedings of the 2nd International Symposium Fan Noise, Senlis, France, September 2003.

[2] S. Bianchi, A. Corsini, and A. G. Sheard, "Installed acoustic performance of cooling axial fans fitted with end-plates," Noise Control Engineering Journal, vol. 60, no. 5, pp. 519-527.

[3] O. Roslyng, "Installation effect on axial flow fan caused by swirl and non-uniform velocity distribution," in Proceedings of the Installation Effects in Ducted Fan Systems Conference, Institution of Mechanical Engineers, Power Industries Division, London, UK, May 1984, AIAA paper 96-0297.

[4] M. Staiger and H. Stetter, "Aerodynamic response of axial fan bladings to non-uniform inlet flow fields," in Institution of Mechanical Engineers Seminar on Installation Effects in Fan Systems, London, UK, 1993.

[5] A. Corsini, A. egiani, S. Minotti, and A. G. Sheard, "Numerical investigation on the aerodynamic influence of eroded leadingedge geometry on boiler fan performance," in Proceedings of the 9th European Conference on Turbomachinery, Fluid Dynamics \& Thermodynamics, pp. 879-892, Istanbul, Turkey, March 2011.

[6] A. Corsini, A. Marchegiani, F. Rispoli, A. G. Sheard, and P. Venturini, "Predicting blade leading edge erosion in an axial induced draft fan," Journal of Engineering for Gas Turbines and Power, vol. 134, article 042601, 9 pages.

[7] A. Corsini, F. Rispoli, A. G. Sheard, and P. Venturini, "The impact of blade erosion on the induced-draft boiler fan aerodynamic performance and stall margin ventilation," in Proceedings of the 57th American Society of Mechanical 
Engineers Turbine and Aeroengine Congress, Copenhagen, Denmark, June 2012, paper no. GT2012-69048.

[8] J. T. Greenzweig, R. Henry, and T. Holm, "The effect on inlet flow distortion on the performance of centrifugal fans for utility applications," in Proceedings of the 56th American Society of Mechanical Engineers Turbine and Aeroengine Congress, Vancouver, Canada, June 2011, paper no. GT2011-45422.

[9] J. A. Teixeira, A. Tourlidakis, P. C. Ivey, A. G. Sheard, J. A. Molin, and I. R. Kinghorn, "Computational analysis of an industrial axial-flow fan including installation effects," in Proceedings of the IMechE Advances of CFD in Fluid Machinery Design Seminar, London, UK, November 2003.

[10] "TASCflow documentation," ANSYS Canada, Ontario, Canada, 2003.

[11] P. F. Galpin and G. D. Raithby, "Numerical solution of problems in incompressible fluid flow: treatment of the temperature-velocity coupling," Journal of Numerical Heat Transfer, vol. 10, no. 2, pp. 105-129, 1986.

[12] M. Pascu, M. Miclea, P. Epple, A. Delgado, and F. Durst, "Analytical and numerical investigation of the optimum pressure distribution along a low-pressure axial fan blade," Journal of Mechanical Engineering Science, vol. 223, no. 3, pp. 643-658, 2009.

[13] R. H. Perkinson, M. C. Soule, and H. J. Holl, "Separator for bearing assemblies with cyclic loads," patent number US8167501, May 2012.

[14] A. G. Sheard and A. Rhoden, "Variable pitch fans," patent no. GB2485634, September 2012. 

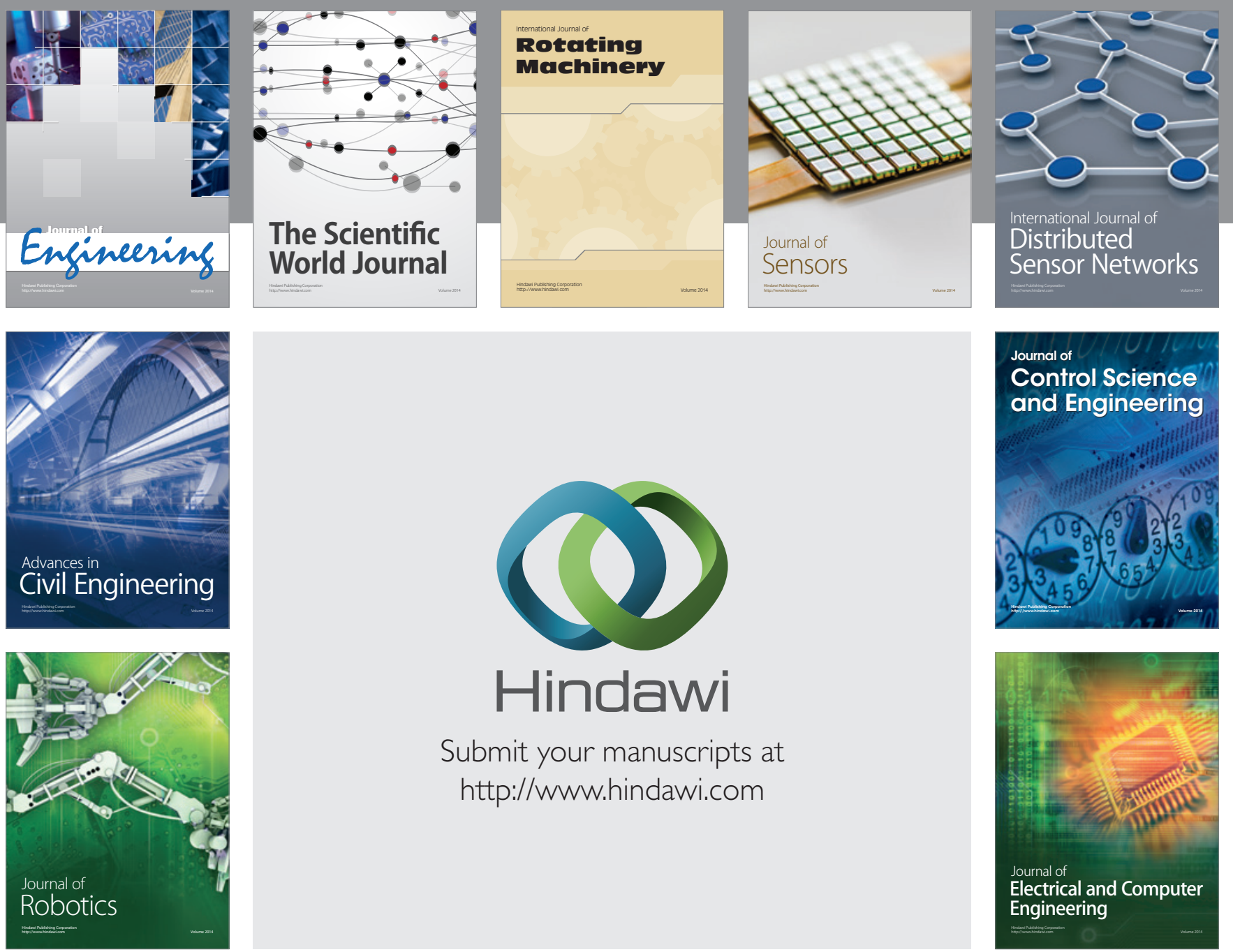

Submit your manuscripts at

http://www.hindawi.com
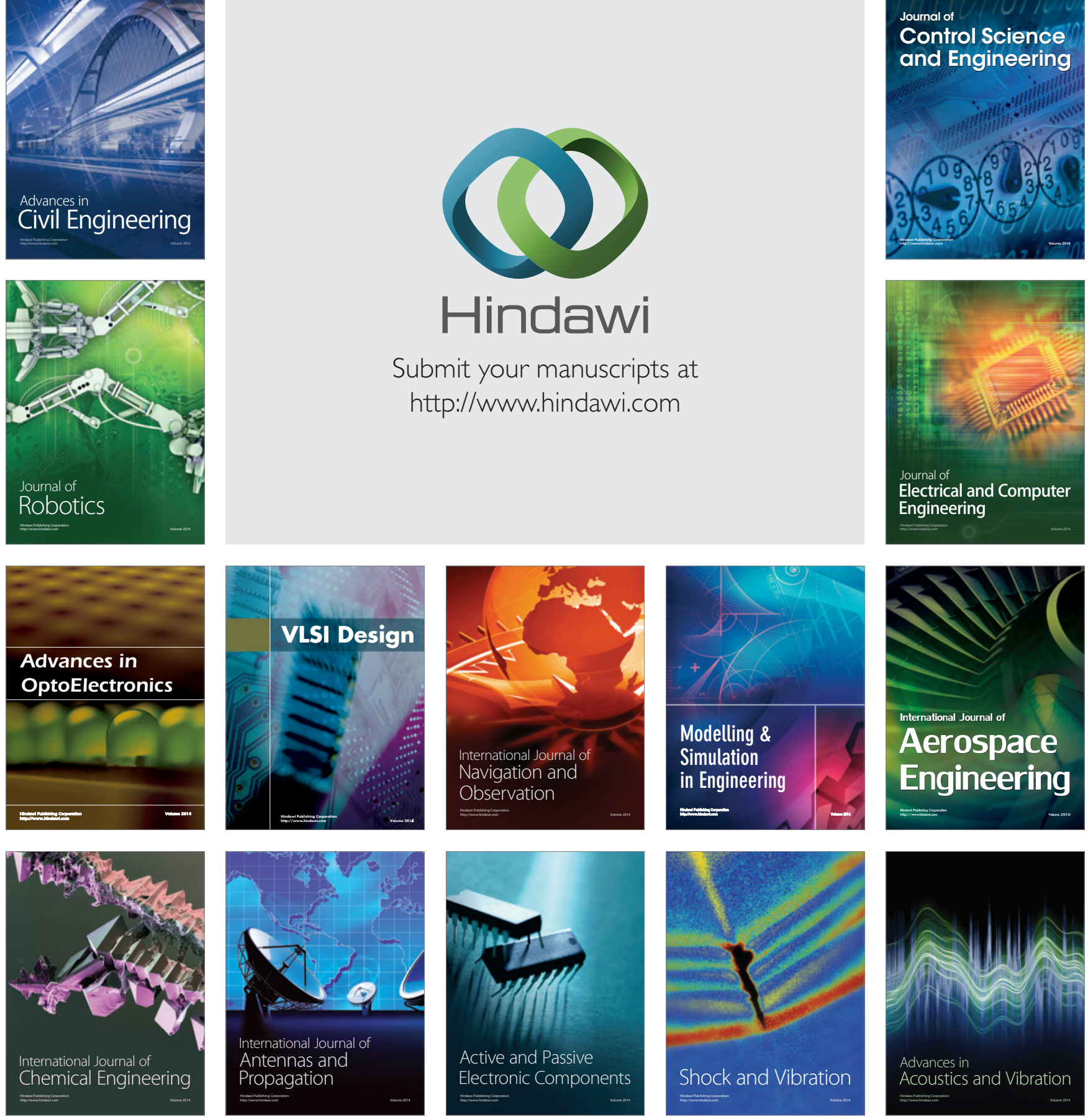